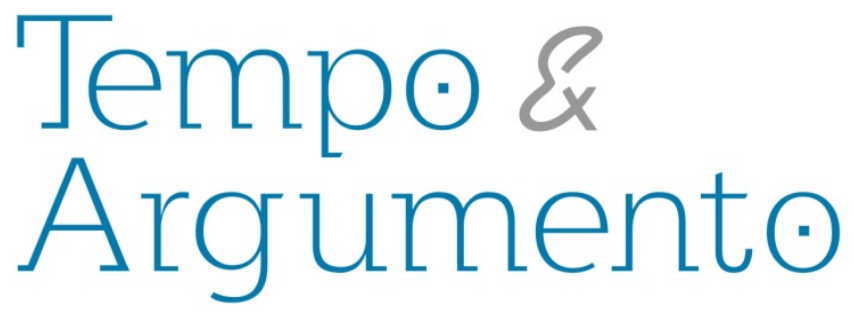

\title{
A campanha pela Anistia em imagens: Tempo Presente, fotografias e repressão política ${ }^{1}$
}

\begin{abstract}
Resumo
O principal objetivo deste artigo é analisar um informe produzido pelo Serviço Nacional de Informação (SNI), em 28 de março de 1978, durante a campanha pela Anistia. A abertura à consulta dos acervos dos órgãos de controle e repressão do regime militar no Brasil, produzidos durante os anos de 1964-1985, permitiu o acesso a milhares de documentos e fotografias.
\end{abstract}

Palavras-chave: Anistia; Ditadura e Ditadores; Brasil História - 1964-1985; Fotografias.

\section{Pedro Ernesto Fagundes}

D outor em História Social pela Universidade Federal do Rio de Janeiro (UFRJ). Professor permanente do Programa de Pós-graduação em História da Universidade Federal do Espírito Santo (PPGHIS UFES). Membro da Comissão de Altos estudos do Projeto Memória Reveladas - Centro de Referência das Lutas Políticas do Brasil (1964-1985). Brasil pefagundes@uol.com.br

\section{Para citar este artigo:}

FAGUNDES, Pedro Ernesto. A campanha pela Anistia em imagens: Tempo Presente, fotografias e repressão política. Revista Tempo e Argumento, Florianópolis, v. 8, n. 17, p. 134 - 153. jan./abr. 2016.

DOI: $10.5965 / 2175180308172016134$

http://dx.doi.org/10.5965/2175180308172016134

\footnotetext{
${ }^{1}$ Essa pesquisa contou com apoio da CNPQ através do Edital MCTI/CNPQ/Universal 14/2014.
} 


\title{
The Amnesty campaign in images: Time present, photographs, political repression
}

\begin{abstract}
The main purpose of this paper is to analyze a report produced by the Serviço Nacional de Informação (SNI), in march 28, 1978, during the Amnesty campaign. The declassification of the documentation of the agencies of control and repression of the military regimen in Brazil, produced during the years 1964-1985, allowed access to thousands of documents and photographs.
\end{abstract}

Keywords: Amnesty; Dictatorships and Dictators; Brazil - History - 1964-1985; Photographs.

\section{O Tempo Presente e suas possiblidades}

O século $X X$ foi marcado por uma série de acontecimentos que reordenaram as bases da sociedade. Acontecimentos como as duas Guerras Mundiais, a era atômica, a conquista do espaço, a Guerra Fria, os acontecimentos de 1968, o colapso do Leste Europeu, o fim dos regimes ditatoriais na América do Sul, por exemplo, impactaram os principais paradigmas da História estabelecida nos primeiros manuais acadêmicos da área, produzidos por Charles Seignobos e Charles Victor Langlois, levando o título original de Introduction aux Études Historiques, datados do século XIX.

Esse turbilhão de acontecimentos provocou efeitos nas bases teóricas e metodológicas do campo da História, principalmente, entre os historiadores franceses. Segundo Rioux (1999), a própria noção de Tempo passaria por um questionamento. Nesse sentido, para os pesquisadores da geração pós-1945, esse conceito adquiriu um sentido renovado, original e ímpar, ou seja, a História poderia ser escrita pelos próprios personagens que estavam vivenciando esses fatos. 
A partir da segunda metade da década de 1950, muitos historiadores começaram a externar suas opiniões sobre os acontecimentos imediatos utilizando os meios de comunicação, com destaque para os jornais, rádios e televisão. Os avanços tecnológicos proporcionaram uma intensa aproximação dos historiadores com as análises dos fatos do presente.

Entretanto, foi com o movimento de "retomada" da História Política, durante a década de 1970, que surgiram as bases teóricas da História do Tempo Presente. Esse movimento teve seu ápice em 1978 quando foi criado - sob a direção de François Bedárida - o Institut d'Histoire du Temps Présent (IHTP). Inicialmente, esse espaço teve que "defender a sua legitimidade científica", principalmente, acerca de questões sobre sua temporalidade, sua objetividade e sua relação com as fontes. Participaram dessa

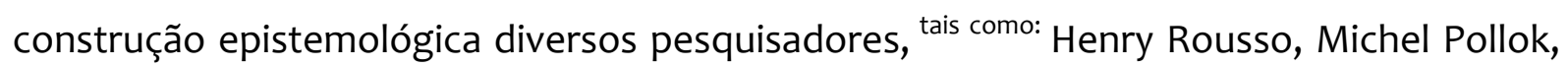
Denis Peschanski, Pierre Laborie, Jean-François Sirinelli, Paul Ricouer, Pierre Nora, Philipi Joutard, Sege Berstein, entre outros².

Durante as décadas de 1980 e 1990, buscando embasar seus princípios científicos, foram realizados estudos sobre testemunho, jornalismo e história, imagens, história oral, memórias coletivas, trauma, comemorações e usos políticos do passado. Houve um acúmulo de estudos sobre os chamados "grandes eventos", tais como o Mundo pósSegunda Guerra Mundial, os processos de descolonização, as memórias coletivas sobre os passados traumáticos.

Esses estudos - somados ao contexto do fim dos regimes do bloco soviético, do Apartheid na África do Sul e das ditaduras na América do Sul - reverberaram na sociedade ampliando o interesse pelas questões do chamado Tempo Presente. Definitivamente, a partir da década de 1990, ações de caráter efetivo e simbólico (anistias, criação de leis de reparação, edificação de monumentos, abertura de centros de memória, etc.) passaram a compor o cotidiano político nos mais diferentes continentes.

Nesse mesmo sentido, em diversos países, o destino, a salvaguarda e a utilização dos documentos dos arquivos das antigas polícias políticas deu origem a decretos, leis,

\footnotetext{
${ }^{2}$ DELACROIX; DOSSE; GARCIA, 2012.
} 
Durante essa década, em diferentes partes do mundo que haviam passado por regimes autoritários, diversos setores da sociedade - familiares de mortos e desaparecidos, historiadores, arquivistas, juristas, entre outros - pressionaram os Governos no sentido da abertura dos chamados "arquivos das ditaduras" 3 . Esse movimento possibilitou que fundos documentais de diversos países que passaram por experiências ditatoriais - do Leste Europeu, da Espanha Franquista e das ditaduras militares sul-americanas - outrora secretas, passassem por modificações em relação a leis de acesso, organização e utilização dos fundos documentais. Para a área da História do Tempo Presente, essa documentação representou um acontecimento sem precedentes: o contato com um conjunto documental originário dos arquivos dos antigos órgãos de repressão.

No Brasil, sobretudo nas últimas duas décadas, as controvérsias sobre a Ditadura Militar (1964-1985) reacenderam-se com a passagem dos 50 anos do golpe de 1964. A rememoração desse período foi pontuada por uma série de iniciativas no âmbito do Poder Público e da sociedade civil, entre elas: instalação de comissões da verdade, aumento do volume de estudos acadêmicos, comemorações e aprovação de uma nova legislação sobre o acesso à informação.

Em nosso país, um dos impactos dessa nova demanda foi o acesso a um inédito conjunto documental sobre esse período traumático da história recente, inclusive a conjuntos fotográficos produzidos pela comunidade da informação. A apresentação dos conceitos teóricos acima mencionados foi importante, pois, as fontes que passaremos a analisar têm ligação direta com o passado recente do Brasil.

O conjunto documental que analisaremos faz parte do acervo do Serviço Nacional de Informação (SNI) ${ }^{4}$. Esse órgão, criado poucos meses depois do Golpe de 1964, materializou a repressão política durante o período da Ditadura Militar. Somente em 2012,

${ }^{3}$ KECSKEMÉTI, 2015.

${ }^{4}$ Para maiores informações sobre o SNI, ver em: ISHAQ; FRANCO; SOUSA, 2012. 

$12.523 / 2011)$.

Concretamente, a sanção da Lei $n^{\circ} 12.527 / 2011$ junto com a Lei $n^{\circ}$ 12.528/11 (criando a Comissão Nacional da Verdade), ambas em 18 de maio de 2012, foram em décadas as mais contundentes ações do Estado Brasileiro em torno da demanda sobre a abertura dos arquivos sigilosos, produzidos durante a Ditadura, em nosso país. A maior das expectativas repousava sobre a possibilidade de “... consultar uma extensa massa documental que versa não apenas sobre atividades de perseguição, controle social e repressão política, mas também sobre as distintas esferas de atuação dos grupos de esquerda". 5

Nesse novo contexto, o contato com o conjunto documental analisado no artigo aconteceu em 2014, durante uma pesquisa realizada no acervo do antigo SNI, que atualmente encontra-se custodiado no Arquivo Nacional, nas suas sedes de Brasília e do Rio de Janeiro. O documento analisado foi a Informação nº 029/116/ARJ/78, que apresenta informações sobre um ato público realizado nas dependências da Pontifícia Universidade Católica do Rio de Janeiro (PUC/RJ), em março de 1978. Apesar de a parte final do documento relatar que foram anexadas 13 fotografias e uma fita cassete com áudio do evento, no acervo Arquivo Nacional (AN), encontramos apenas quatro fotografias no referido documento. A seguir, antes de analisarmos as fotografias, apresentaremos o contexto histórico da assim chamada Abertura Política brasileira.

\section{A Abertura Controlada e as mobilizações pela Anistia Ampla, Geral e Irrestrita}

Durante a segunda metade da década de 1970, após quase uma década no poder, o governo militar, implantado após o golpe de 1964, apresentou os primeiros sinais do esgotamento. Essa época foi marcada por contradições e crises políticas e econômicas. São inúmeros os fatores que marcaram o esgotamento das relações entre o regime

\footnotetext{
${ }^{5}$ Para maiores informações sobre a Lei de Acesso a Informação, ver em: JOFFILY, 2012.
} 
militar e a sociedade civil. Entre esses fatores, podemos citar: o resultado das eleições de 1974 - amplamente favorável para o Movimento Democrático Brasileiro (MDB); o fim do chamado "Milagre Brasileiro" e consequentes desdobramentos no âmbito econômico, como o crescimento da inflação; as constantes denúncias de casos de tortura, morte e desaparecimento - com destaque para o caso do jornalista Vladimir Herzog. Em seu conjunto, esses fatores serviram para desgastar o apoio de contingentes expressivos da sociedade em favor da ditadura.

Na tentativa de contornar e controlar as "tensões da Abertura", a cúpula militar deu início a uma série de articulações visando uma distensão lenta, controlada e segura. 0 primeiro movimento do Governo Militar, nesse sentido, ocorreu logo após a posse na Presidência da República do general Ernesto Geisel (1974-1979). Entretanto, segundo Kinzo (1988), esse momento de "Distensão" foi marcado por uma "Abertura Controlada".

A atuação da cúpula militar como os "atores centrais" no projeto político é destacada pela memória dos próprios participantes dos governos dos generais Ernesto Geisel (1974-1979) e João Baptista Figueiredo (1979-1985). Segundo esses militares, o sucesso da abertura política - apesar da interferência "inoportuna” dos líderes civis deve-se à atuação da dupla Ernesto Geisel-Golbery do Couto e Silva. Ainda a partir dessa interpretação, ambos teriam coordenado a disputa contra a chamada "linha dura" dos militares - representada pela Comunidade de Informações: Centro de Informação do Exército (CEI), o Centro de Informação e Segurança da Aeronáutica (CISA) e o Centro de Informação da Marinha (CENIMAR), Destacamentos de Operações de Informação Centros de Operações de Defesa Interna (DOI-CODI), etc. $)^{7}$ e devolveram à sociedade civil o Estado de Direito. (D’ARAÚJO, 1995)

Para esses setores militares, as tarefas fundamentais do projeto foram desencadeadas, coordenadas e controladas por cima, sem a intervenção dos grupos civis, nem mesmo de parlamentares da Aliança Renovadora Nacional (ARENA). Assim, do ponto de vista dos atores militares, pretendeu-se claramente um processo de abertura

\footnotetext{
${ }^{6}$ KINZO, 1988.

${ }^{7}$ Para maiores informações, ver em: ISHAQ; FRANCO; SOUSA, 2012.
} 
"lento e seguro" e conduzido pelo alto, do qual estariam excluídas as forças de oposição. (D’ARAÚJO, 1995).

Por outro lado, esse período também teve diversos episódios marcados pelo uso da força - da lei e das armas - contra os setores da oposição. Entre eles podemos citar: a operação final contra a guerrilha do Araguaia; a onda repressiva contra os dirigentes do Partido Comunista Brasileiro (PCB); os episódios das mortes de Vladimir Herzog (1975) e do metalúrgico Manoel Fiel Filho (1976); a chacina da Lapa que, em dezembro de 1976, vitimou dirigentes do Partido Comunista do Brasil (PCdoB) reunidos em São Paulo; a cassação do mandato de diversos parlamentares do MDB; o fechamento do Congresso Nacional e a edição do "Pacote de Abril", ambos em $1977 .{ }^{8}$

Entretanto, é necessário diferenciar a Lei da Anistia dos chamados "movimentos pela anistia", pois, apesar de todos os esforços do Governo Militar, a oposição nesse momento também ganhou musculatura organizacional. Destaque para a atuação da ala progressista da Igreja Católica, representantes do "novo sindicalismo"9 e, como veremos a seguir, para os militantes do movimento estudantil. Um dos acontecimentos marcantes nesse período foi a criação do Movimento Feminino pela Anistia (MFPA), no final de 1975. (DEL PORTO, 2002).

O surgimento do MFPA coincide com a celebração do Ano Internacional da Mulher (1975) e com as comemorações dos 30 anos da anistia política após o fim da ditadura do Estado Novo (1937-1945). Lideradas por Therezinha Godoy Zerbini, um grupo de mulheres paulistas, fundou em 23 de junho de 1975, o primeiro núcleo da entidade. O aparecimento do MFPA evidenciou o pioneirismo feminino na campanha pela Anistia no Brasil. (BARRETO, 2011).

Nos anos seguintes foram criados núcleos do MFPA em diversos estados, tais como: São Paulo, Rio de Janeiro, Minas Gerais, Ceará, Pernambuco, Rio Grande do Sul, entre outros. Entre as atividades das militantes da entidade, estavam atividades de mobilização, atos públicos, lançamento de manifestos e até a edição de um jornal, em 1977, chamado “Maria Quitéria”. Através da participação de Therezinha Zerbini em

\footnotetext{
${ }^{8}$ Para maiores informações sobre o "novo sindicalismo", ver em: SANTANA, 2001.

${ }^{9}$ Para maiores informações sobre as crises do processo de Abertura, ver em: SILVA, 2003.
} 
eventos sobre direitos humanos em outros países, o MFPA conseguiu divulgar internacionalmente a campanha pela Anistia Política.

Outro marco nas mobilizações em favor da Anistia ampla, geral e irrestrita foi o surgimento, em 14 de fevereiro de 1978, do Comitê Brasileiro pela Anistia (CBA). A partir da criação do CBA, foi sendo estruturado um movimento articulado nacionalmente, através dos comitês de apoio à Anistia, em quase todos os estados do país e até mesmo em outros países, entre eles: Portugal, Itália, França e Bélgica. Com objetivo de agregar todos os setores nas mobilizações, os núcleos do CBA permitiram a participação de parentes de mortos e desaparecidos, estudantes, jornalistas, religiosos, sindicalistas, militantes dos direitos humanos e diversos outros setores da sociedade envolvidos na campanha pela Anistia Ampla, Geral e irrestrita.

Entre as diversas lideranças que participaram da CBA podemos citar: Helena Grecco (CBA /MG), Iramaia de Queiroz Benjamim (CBA/RJ), Luiz Eduardo Greenhalg (CBA/SP) e Diana Cunha Mendonça (CBA/BA). Entre 1978 e agosto de 1979, mês da tramitação e aprovação da Lei $n^{\circ}$ 6683/79, no Congresso Nacional, esses comitês realizaram reuniões, manifestações, congressos, encontros, seminários, enfim, um conjunto de atividades que tiveram como principal bandeira a Anistia ampla, geral e irrestrita. (GRECCO, 2003).

Era esse o cenário político durante os meses inicias de 1978, quando a maioria das entidades estudantis brasileiras intensificou sua participação mais efetiva nas mobilizações pela Anistia ampla, geral e irrestrita. Como veremos a seguir, o dia 28 de março daquele ano significou um marco histórico durante esse processo político.

O dia 28 de março representa uma das mais importantes datas do calendário político do Movimento Estudantil brasileiro. Nesse dia, em 1968, foi assassinado no Rio de Janeiro, durante um protesto no restaurante estudantil Calabouço, o estudante secundarista Edson Luiz Souto. Após esse trágico acontecimento, as entidades estudantis transformaram essa data num símbolo da luta estudantil em defesa da Democracia. Uma década depois, os dirigentes estudantis escolheram essa data para realizar as primeiras 
As atividades convocadas pelo Movimento Estudantil (ME) ocorreram em diversas partes do país, como destacou o jornal Folha de São Paulo ${ }^{10}$. Na primeira página da sua edição do dia 29 de março de 1978, o jornal paulistano apresentou uma pequena foto com a seguinte legenda: "sem incidentes em São Paulo". A imagem era do culto ecumênico, que teria reunido quatro mil estudantes em frente à Faculdade de Medicina da USP, em homenagem a Edson Luiz e Alexandre Vannucchi Leme, estudante do curso de Geologia (USP), morto em 1973, pela repressão política.

O conteúdo da matéria ressaltou o caráter nacional das manifestações organizadas pela Comissão Pró-União Nacional dos Estudantes (CP UNE). A CP UNE surgiu como principal deliberação do conturbado III Encontro Nacional de Estudantes (III ENE), em setembro de 1977, na PUC/SP ${ }^{11}$. Mesmo sofrendo com a forte repressão das forças de segurança paulista, representes estudantis de diversas partes do país conseguiram aprovar a criação da CP UNE. A entidade contava com representantes de inúmeros Diretórios Centrais dos Estudantes e Uniões Estaduais de Estudantes (DCE's e UEE's).

A CP UNE deveria realizar duas atividades prioritárias. Em primeiro lugar, a rearticulação do ME brasileiro rumo à reabertura da sua entidade geral mais tradicional: a UNE. Em segundo, unificar as ações políticas dos militantes estudantis em torno das mobilizações pela Anistia ampla, geral e irrestrita.

Apesar da existência de diversas forças políticas e tendências no meio estudantil, houve uma adesão massiva das entidades estudantis durante as mobilizações em torno do dia 28 de março de 1978. Haja vista como as matérias dos jornais informaram que em todas as manifestações foi realizada a leitura do manifesto da CP-UNE. Assim, essa data foi caracterizada pela maior mobilização - depois de muitos anos - do ME brasileiro em torno de uma palavre-de-ordem unificada: a Anistia. Como destacaremos mais adiante, essa mudança no nível de organização e na postura política dos militantes estudantis chamou a atenção também dos órgãos de informação.

\footnotetext{
${ }^{10}$ Folha de São Paulo, 29 de março de 1978, p. 1 e 17.

${ }^{11}$ Para saber mais sobre a invasão da PUC/SP em 1977, ver em: CANCIAN, 2010.
} 
Ainda segundo a Folha de São Paulo, o Centro Acadêmico (CA) 11 de agosto realizou uma série de atividades nas dependências da Faculdade de Direito da USP. Durante todo o dia, os estudantes promoveram debates, passaram nas salas de aula, realizaram leitura de moções de apoio e fizeram diversos discursos num espaço que o jornal chamou de “tribuna livre". Na página 17, com o título “Estudantes manifestam-se”, o texto do jornal registra que os estudantes também estavam na rua defendendo a Anistia Política. Prova disso foi a mesa-redonda que contou com a presença de centenas de estudantes na Escola Politécnica da USP. Estiveram presentes e expuseram sua posição sobre o tema Alberto Goldman - o deputado emedebista - e Therezinha Zerbini - advogada e líder do Movimento Feminista pela Anistia (MFPA).

Durante todo o ato, demonstrando a amplitude política e apoio externo ao ME, foram lidos manifestos e notas de apoio de entidades e organizações dos mais diversos setores, entre eles a Oposição Sindical dos Metalúrgicos de São Paulo, Comissão de Mães em defesa dos Direitos Humanos, Pastoral Operária (PO), Associação Nacional dos Médicos Residentes e Oposição dos Professores do Estado de São Paulo.

Sem nenhuma fotografia ou chamada na primeira página, o jornal O Globo, de 29 de março de 1978, reservou para as atividades do ME uma matéria na página 8 com o seguinte título: “Estudantes voltam a fazer manifestações”. No texto, são apresentadas as principais atividades estudantis realizadas em nível nacional. ${ }^{12}$

A matéria procura relatar a realização dos mais diversos tipos de atividades (leitura de manifestos, concentração de estudantes, mesas-redondas, debates, apresentações teatrais, etc.) que ocorreram nas cidades do Rio de Janeiro, São Paulo, Belo Horizonte, Salvador, Brasília, Vitória e Porto Alegre. O destaque maior da matéria foi sobre o ato realizado na PUC/RJ que, como o evento na Escola Politécnica da USP, teve como tema central a campanha da Anistia Política. A concentração reuniu centenas de estudantes e teve a duração de, aproximadamente, duas horas. O jornal reporta que, entre as diversas faixas estendidas nas dependências da universidade, uma reivindicação se destacava: a Anistia.

\footnotetext{
${ }^{12}$ O Globo, 29 de março de 1978, p. 8.
} 
Importante relatar que o ato se iniciou com o brado da palavra-de-ordem pelos presentes: “Anistia: ampla, geral e irrestrita”. A atividade contou também com apresentações teatrais, discursos, leitura de notas de apoio e distribuição de uma lista com 161 nomes de desaparecidos políticos. Como nos atos em outras universidades, também na PUC/RJ foi apresentado o manifesto da CP-UNE.

Com a manchete "Estudantes reverenciam colegas com apelo pela Anistia”, o Jornal do Brasil (JB), de 29 de março de $1978^{13}$, apresentou uma reportagem sobre as manifestações do dia anterior pelo país. Ainda segundo esse periódico, centenas de alunos da Escola de Comunicação da UFRJ, todos com tarjas pretas, estenderam uma faixa com os dizeres: “Companheiro jornalista Herzog, presente!”. Durante os eventos da UFRJ, ainda segundo o JB, foram lidas moções de repúdio e notas de apoio em referência a variados assuntos em pauta. Especial atenção para a nota de apoio aos presos políticos brasileiros.

Demonstrando a articulação dos estudantes e, principalmente, das atividades convocadas pela CP-UNE, com a principal mobilização política do país naquele momento, esteve presente no ato Iramaia Queiroz Benjamim - representante do Comitê Brasileiro pela Anistia (CBA) - que, nas palavras do JB, foi "prestar solidariedade ao movimento". Um dos símbolos das mobilizações pela Anistia ampla, geral e irrestrita, Iramaia de Queiroz Benjamim, nasceu em 23 de novembro de 1923, no Rio de Janeiro. Em 1978, foi uma das fundadoras do Comitê Brasileiro pela Anistia (CBA/RJ). Teve dois filhos - Cesar e Cid Benjamim - na lista de presos políticos. Esteve à frente das principais iniciativas em favor da Anistia ampla, geral e irrestrita. Por isso mesmo, depois da aprovação da Lei $\mathrm{n}^{\circ}$ 6683, de 28 de agosto de 1979, tornou-se uma das maiores críticas da chamada Lei da Anistia. Mesmo assim, continuou sua militância em defesa dos direitos humanos. ${ }^{14}$

Depois de apresentar um rápido histórico da CP-UNE, o jornal informa que o manifesto foi elaborado pela organização para ser lido "em todas as manifestações do país". A matéria enfatiza a participação da CP-UNE como entidade responsável pela organização e coordenação das atividades convocadas e realizadas nacionalmente. 0

\footnotetext{
13 Jornal do Brasil, 29 de março de 1978, p. 16.

${ }^{14}$ Para maiores informações sobre Iramaia de Queiroz Benjamim, ver em: BENJAMIN; AUTRAN, 1982.
} 
mesmo jornal reporta que a maior concentração de estudantes no estado do Rio de Janeiro foi registrada no ato realizado nas dependências da PUC/RJ. Essa atividade reuniu algo em torno de 400 (quatrocentos) participantes, entre estudantes, parlamentares do MDB - como o deputado estadual Edson Kler e Antonio Carlos de Carvalho -, representantes do jornal Brasil Mulher, do jornal Movimento e do jornal Em Tempo.

Apesar da ampla cobertura do JB e do O Globo, as imagens do ato na PUC-RJ que apresentaremos a seguir não foram publicadas em nenhum desses periódicos. As quatro fotografias que iremos analisar fazem parte de um documento produzido pela Agência Rio de Janeiro do Serviço Nacional Informação (SNI).

A Informação nº 029/116/ARJ/78, datada de 31 de março de 1978, compõe o acervo do SNI. Esse documento apresenta um resumo das principais atividades que aconteceram nas dependências da PUC/RJ, como por exemplo, o horário do início (12h3omin) e do término da atividade (14h3omin). Reporta ainda que a concentração teria reunido aproximadamente 400 pessoas nos pilotis da sede da universidade - verdadeiro espaço simbólico dessa instituição de ensino. Apresenta também a pauta do evento, assim dividida: informes; leitura de notas de apoio; discursos e leitura de documentos de parentes de presos políticos.

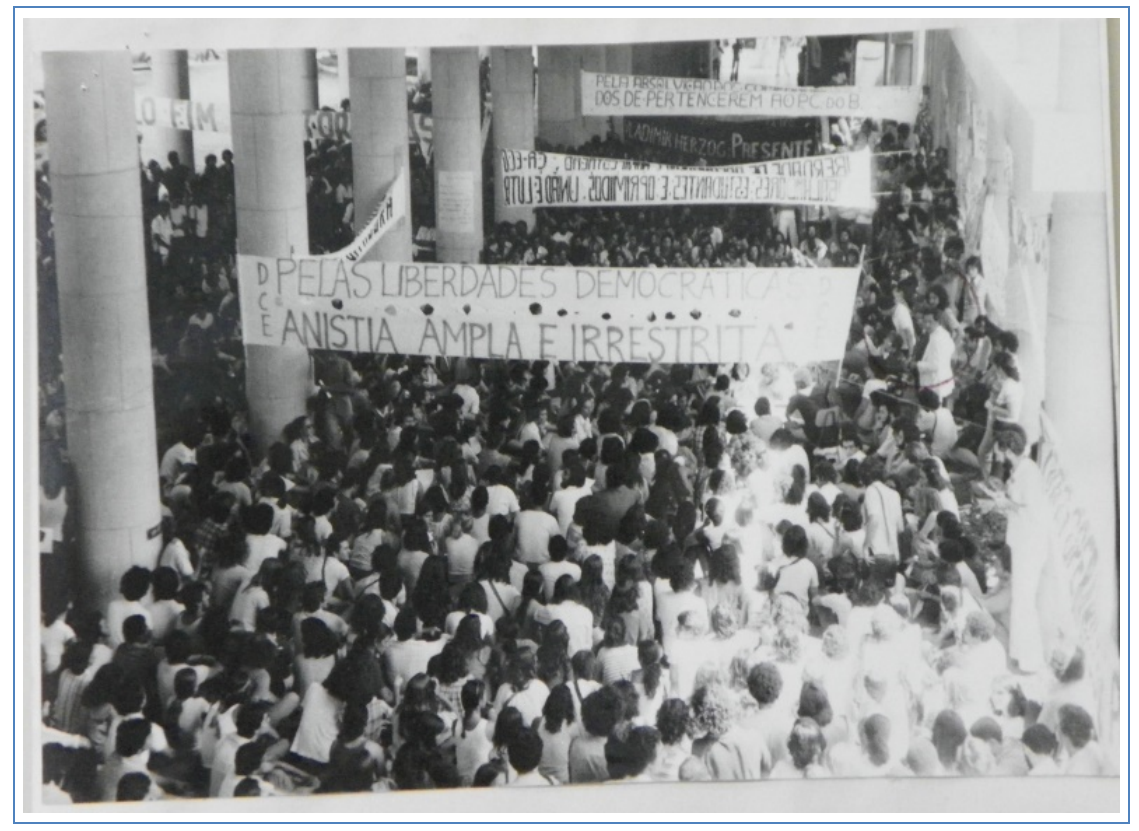

Fotografia $n^{\circ} 1$

Ato público pela anistia na PUC/RJ. Rio de Janeiro, 28 de março de 1978. Arquivo Nacional, Serviço Nacional de Informação. 


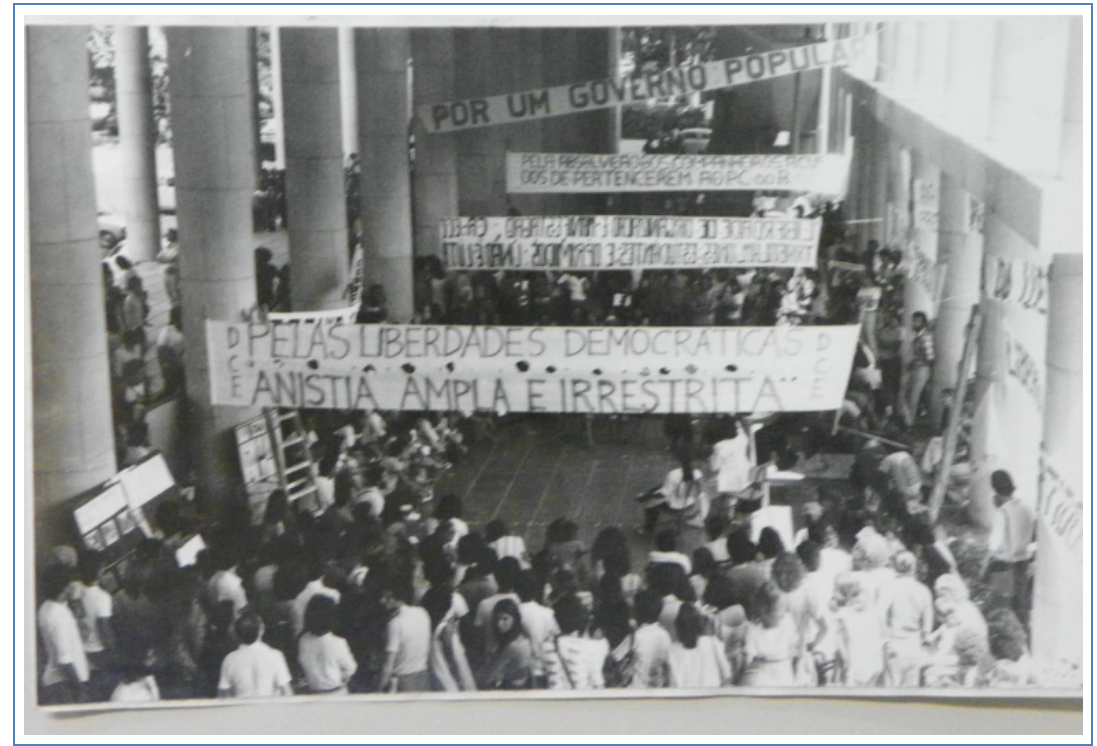

Fotografia $n^{\circ} 2$

Ato público pela anistia na PUC/RJ. Rio de Janeiro, 28 de março de 1978. Arquivo Nacional, Serviço Nacional de Informação.

As fotografias $\mathrm{n}^{\text {os }} 1$ e 2 apresentam uma vista panorâmica da manifestação em dois momentos distintos. A fotografia $n^{\circ} 2$ foi tirada de um ângulo dos pilotis da PUC/RJ, provavelmente durante os discursos e leituras de nota de apoio. Nota-se que a maioria do público está em pé. Apesar de a fotografia $\mathrm{n}^{\circ} 2$ apresentar um ângulo semelhante ao da fotografia $n^{\circ} 1$, essa imagem registrou outro momento da manifestação.

Na fotografia $n^{\circ} 1$ é possível observar que a maioria do público, em maior número que na imagem seguinte, está sentado no chão. Apesar de a maioria dos participantes do ato público ser formada de estudantes, chama atenção o fato de que há faixas que apresentam palavras de ordem sobre a Anistia. Em sequência, o documento do órgão de informação registra a participação de dirigentes estudantis de outras instituições como os representantes do DCE/UFF Marcio Silveira Lemgruber e Luiz Carlos Azedo, e de um representante do DCE da Universidade Federal Rural do Rio de Janeiro.

Foram registradas as presenças de parlamentares do MDB, entre eles: Edson Khair (deputado estadual), Coimbra de Melo e Antonio Carlos de Carvalho (vereadores). Apesar de não citar nomes, também são destacadas as presenças de representantes do Instituto de Estudos Sociais do MDB, de representantes da organização trotskistas Convergência Socialista e de jornalistas dos jornais alternativos Brasil Mulher, Movimento e Em Tempo. 
$\mathrm{Na}$ fotografia $n^{\circ} 3$, é possível visualizar algumas faixas estendidas com as mais diversas palavras de ordem, entre elas: Pelas Liberdades Democráticas - Anistia, Ampla e irrestrita; Por um Governo Popular; Pelo Fim da Tortura e Abaixo a Ditadura. Nos pilotis, ainda se pode ver cartazes e painéis afixados com recortes de jornais e imagens alusivas as mobilizações de 1968. Ainda na fotografia $n^{\circ} 3$ nota-se que alguns dos presentes tiveram o rosto circulado, provavelmente, com uma caneta esferográfica de tinta preta.

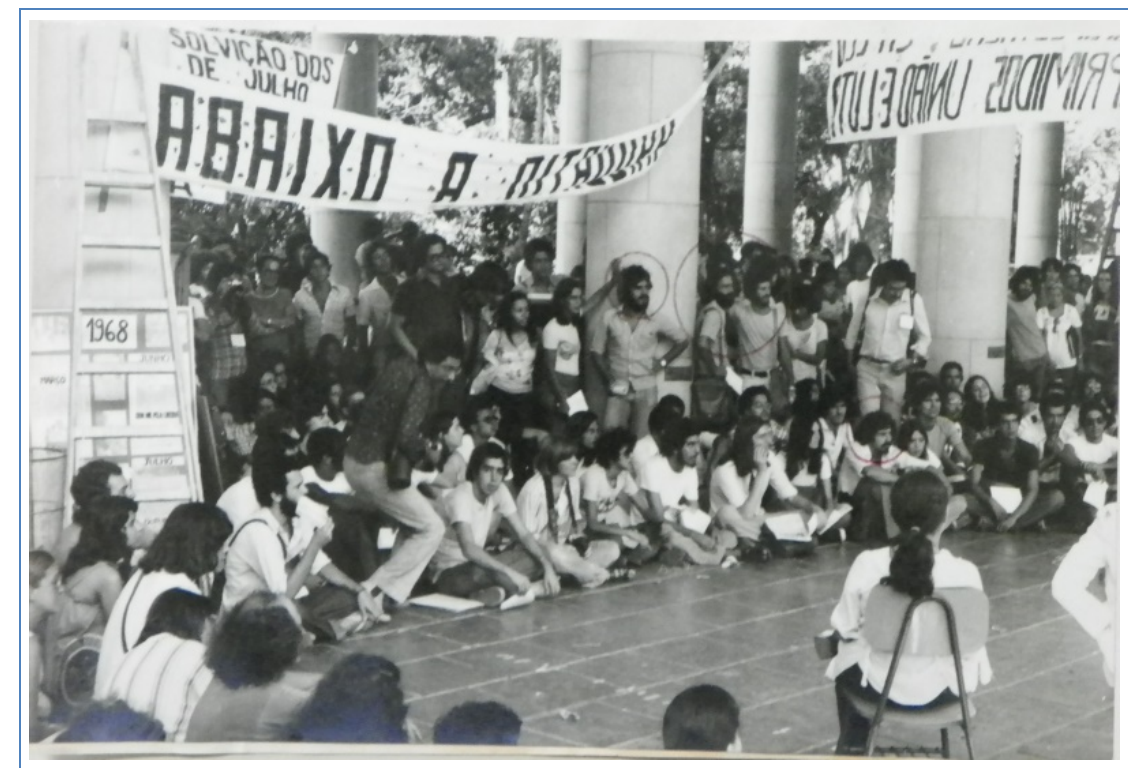

Fotografia $n^{\circ} 3$

Ato público pela anistia na PUC/RJ. Rio de Janeiro, 28 de março de 1978. Arquivo Nacional, Serviço Nacional de Informação.

A forma detalhada da descrição do ato na PUC/RJ, inclusive com a identificação de nomes de presentes num evento que reuniu centenas de participantes, indica que as fotografias produzidas e anexadas à Informação $n^{\circ}$ 029/116/ARJ/78 tinham um objetivo muito específico: identificar os chamados "elementos subversivos". Tal situação é mais explícita na fotografia $n^{\circ} 4$, principalmente no verso da fotografia. Essa fotografia traz a imagem centralizada da "mesa" do ato público, com destaque para os círculos em torno do rosto de cinco participantes. Além disso, todos os rostos dos integrantes da mesa receberam letras $(A, B, C D$ e $E)$, desta vez com uma caneta esferográfica de tinta vermelha. 


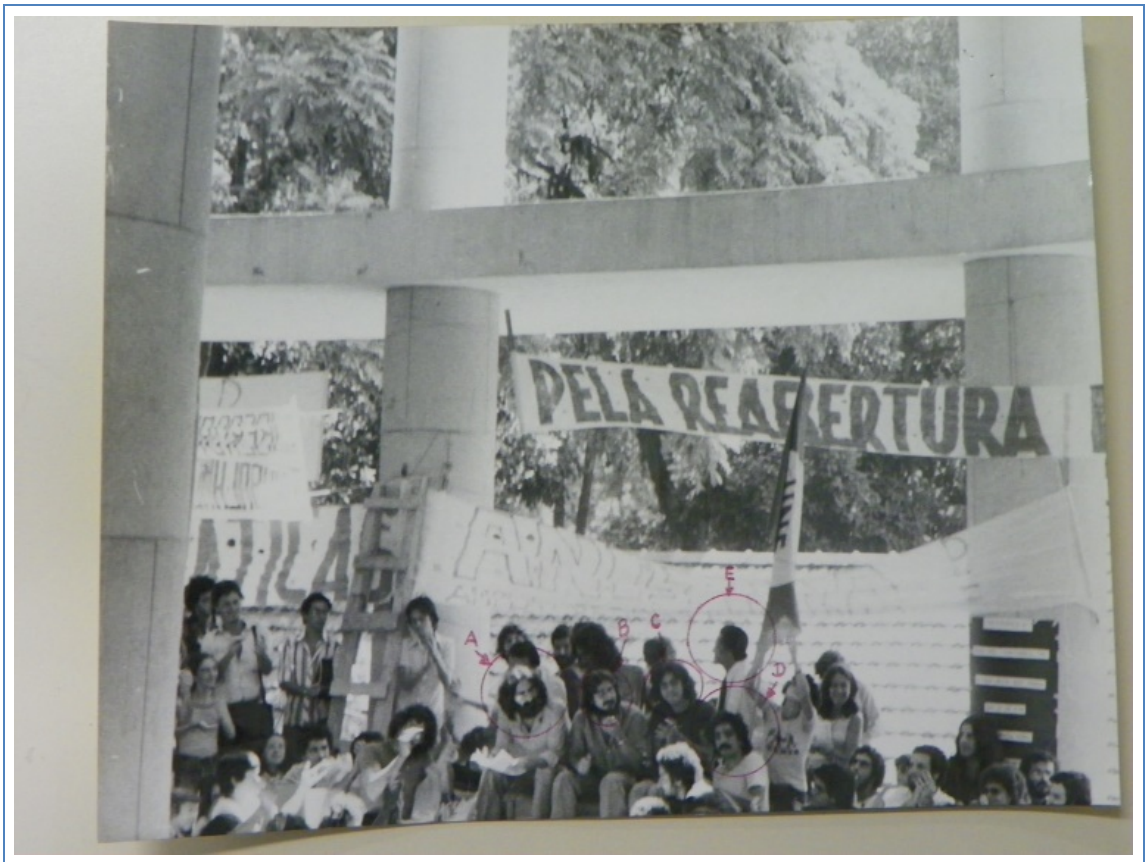

Fotografia $n^{\circ} 4$

Ato público pela anistia na PUC/RJ. Rio de Janeiro, 28 de março de 1978. Arquivo Nacional, Serviço Nacional de Informação.

No verso da fotografia $n^{\circ} 4$, é possível visualizar algo que diz muito sobre a finalidade prática das fotografias para os agentes da repressão. No espaço foram escritas as letras e os respectivos nomes dos participantes da mesa do ato público. Assim, é possível descobrir que a elaboração da Informação $n^{\circ}$ 029/116/ARJ/78 seguiu a mesma sequência do registro do verso da fotografia $n^{\circ} 4$. A análise do conjunto documental, informe e fotografias, indica que ambos serviam para a mesma finalidade: tipificar um crime político.

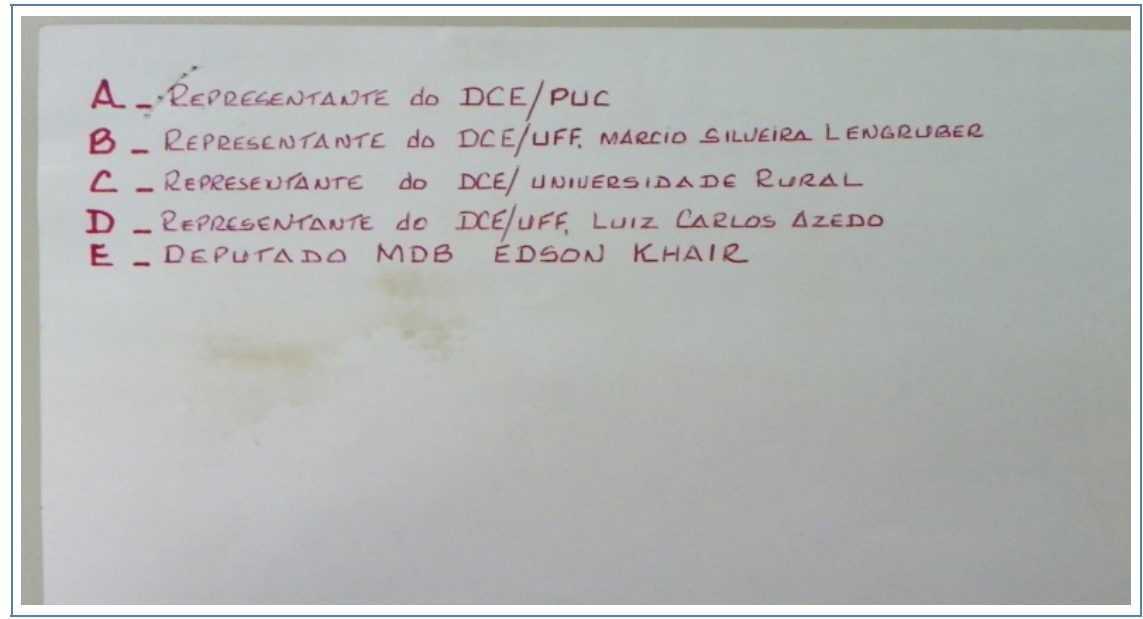

Verso da Fotografia $n^{\circ} 4$

Ato público pela anistia na PUC/RJ. Rio de Janeiro, 28 de março de 1978. Arquivo Nacional, Serviço Nacional de Informação. 


\section{Fotografia e crime político}

Aparentemente, durante as atividades rotineiras dos órgãos de informação, a produção de fotografias serviu para uma tarefa fundamental: identificar e tipificar os “elementos subversivos”. Entretanto, é necessário contextualizar a produção da fotografia como algo semelhante à produção de um texto. Analisar, assim, o estoque de signos presentes nas fotografias, consiste em observar que alguns desses signos estariam nos gestos, atitudes, expressões, cores, efeitos especiais, enfim, cada fotografia estaria repleta de certos significados pertencentes a uma determinada prática social inserida em determinado contexto histórico de sua produção. (CARDOSO e MAUAD, 1997) 1997).

No presente, a análise do conjunto documental da "Comunidade de Informação" fornece uma nova perspectiva para problematizarmos fatos e acontecimentos do período da Ditadura Militar. São instrumentos que possibilitam observar a forma como os agentes da repressão interpretavam as atividades, como construíam o imaginário sobre esses militantes e como utilizavam essas informações em suas atividades de vigilância. $\mathrm{Na}$ atualidade, a utilização de tais fontes produz uma série de interrogações: Quem as produziu? Em que condições? Por qual motivo? O que relatam?

Como dissemos, quem produziu o documento foi a Agência Rio de Janeiro do SNI $(\mathrm{ARJ} / \mathrm{SNI})$. Também vimos que, aparentemente, nenhuma das fotografias anexadas à Informação $n^{\circ}$ 029/116/ARJ/78 foi publicada nos periódicos da capital carioca. Importante registrar que todas as fotografias são em preto e branco e medem $15 \times 20 \mathrm{~cm}$.

Tendo em vista a nitidez das imagens, como indica a fotografia $n^{\circ} 1$, podemos supor que as fotografias foram tiradas de uma distância muito curta. Assim, as condições indicam que um agente "disfarçado de fotógrafo" foi o responsável pelas imagens. Como enfatizamos anteriormente, a forma detalhada da descrição do ato na PUC/RJ aponta que as fotografias produzidas e anexadas à Informação $\mathrm{n}^{\circ}$ 029/116/ARJ/78 tinham um objetivo muito específico: identificar os "elementos subversivos".

Como afirma Kossoy (2003), durante as atividades das polícias políticas a fotografia foi um dos elementos constituintes na elaboração de prontuários das atividades políticas do cidadão. Assim, o ato de registrar um rosto no meio da multidão 
poderia, futuramente, servir como prova do “delito político”. Em algumas situações, os "clássicos" retratos de identificação policial tinha como origem um "retrato involuntário". Como afirma o autor, "enquanto registro da memória política brasileira, a fotografia ocupa um lugar especial nos processos policiais" ${ }^{15}$.

Como indicamos, uma das principais finalidades das fotografias era identificar os militantes da oposição. Dessa forma, ficaria mais fácil acompanhar as atividades desses militantes durante as mobilizações pela Anistia. Igualmente, as imagens serviriam para identificar as lideranças estudantis durante as atividades da agenda política do ME e de outros militantes do movimento social.

Sendo assim, para cumprir essa finalidade, o circuito social das fotografias era a comunidade de informação. Costumeiramente, os documentos dos órgãos de informação contavam com um tópico chamado de "Difusão". Essa era uma prática padronizada em todos os documentos. No caso da Informação nº 029/116/ARJ/78, a parte relativa a esse tópico direcionava o documento para a "Agência Central do SNI".

Provavelmente, o documento e seus anexos foram reproduzidos e enviados para as diversas agências do "serviço" pelo país. Assim, produziu-se um banco de dados que socializou informações e, sobretudo, fotografias de "subversivos" de qualquer região do país. Reforçando essa informação, basta verificar que, segundo o próprio Arquivo Nacional, somente no banco de dados do SNI consta algo em torno de cinco mil fotografias ${ }^{16}$. Essa informação demonstra que a produção de fotografias ocupou um espaço privilegiado no savoir-faire dos agentes da repressão.

\section{Considerações Finais:}

Como enfatizamos, no passado, durante as atividades de monitoramento dos órgãos de repressão, a produção de imagens fotográficas ocupou um espaço destacado entre as atividades dos agentes da comunidade de informação. No presente, a leitura dos

\footnotetext{
${ }^{15}$ KOSSOY, 2003.

${ }^{16}$ Para maiores detalhes sobre a liberação desse conjunto documental, ver em:

http://www1.folha.uol.com.br/poder/2012/07/1115936-fotografias-da-ditadura-sao-liberadas-paraconsulta.shtml
} 
documentos dos arquivos da repressão política fornece a oportunidade de conhecer a forma como a comunidade de informação construiu os estereótipos políticos que deveriam ser monitorados. A finalidade dos documentos e das fotografias era a de justificar a necessidade de permanente vigilância contra a “infiltração comunista”.

A partir desse momento, todos passavam a ser tipificados como suspeitos para os agentes da repressão. Ser fotografado ou ter o nome citado em tais documentos poderia significar que o cidadão passaria a ser rotulado como "subversivo". Ademais, é importante ressaltar que, inicialmente, os acervos da comunidade de informação (fotografias e cartazes) serviram para a repressão compor sua galeria de "suspeitos". Entretanto, na atualidade, esses mesmos conjuntos documentais são uma importante fonte para as pesquisas sobre o passado recente do Brasil.

\section{Referências}

BARRETO, Anna Flávia Arruda Lanna. Movimento Feminino pela Anistia: a esperança do retorno à democracia. Curitiba: CRV, 2011.

BENJAMIN, Iramaia; AUTRAN, Margarida. Ofício de mãe: a saga de uma mulher. Rio de Janeiro: Editora Marco Zero, 1982. (Coleção Nossos Dias, Volume 4).

CARDOSO, Ciro. Flamarion.; MAUD, Ana. Maria. História e imagem: os exemplos da fotografia e do cinema. In: CARDOSO, C. F.; VAINFAS, R.(Org.) Domínios da história: ensaios de teoria e metodologia. Rio de Janeiro: Campus, 1997. p.401-417.

CANCIAN, Renato. Movimento estudantil e repressão política: o ato público na Pontifícia Universidade Católica de São Paulo (1977) e o destino de uma geração de estudantes. São Carlos: EdUFSCar, 2010.

KOSSOY, Boris , O jornalismo revolucionário ilustrado. In: CARNEIRO, Ma Luiza Tucci; KOSSOY, Boris. A imprensa confiscada pelo DEOPS: 1924-1954. São Paulo: Ateliê Editorial; Imprensa Oficial do Estado de São Paulo: Arquivo do Estado, 2003.

KECSKÉMET, Charles. Les Archives des Polices Politiques. Exposé Introductiv. In> CORNU, Marie; FROMAGEAU, Jérôme (Org.). Archives des dictatures: enjeux juridiques, archivistiques et institutionnels. 1ed. Paris: L'Harmattan, 2015. 
D’ARAÚJO, Maria Celina et al.(Orgs.). A volta aos quarteis: a memória militar sobre a abertura. Rio de Janeiro: Relume-Dumará, 1995.

DELACROIX, Christian; DOSSE, François; GARCIA, Patrick. Correntes históricas na França: séculos XIX e XX. Tradução: Roberto F. Leal. Rio de Janeiro: Editora FGV, 2012.

DEL PORTO, Fabiola Brigante. A luta pela anistia no regime militar brasileiro: a constituição da sociedade civil no país e a construção da cidadania. 2002, . Dissertação (mestrado em Ciência Política) - Universidade Estadual de Campinas, Departamento de Ciência Política do Instituto de Filosofia e Ciências Humanas, Campinas, 2002.

KINZO, Maria D’alva G. Oposição e autoritarismo: gênese e trajetória do MDB (19661979). São Paulo: Vértice; Editora dos Tribunais, 1988.

GRECO, Heloísa. Dimensões fundacionais da luta pela anistia. 2012, . Tese (doutorado em História) - Universidade Federal de Minas Gerais, Curso de Pós-graduação da Faculdade de Filosofia e Ciências Humanas, Belo Horizonte, 2003.

ISHAQ, Vivian; FRANCO, Pablo Endricio; SOUSA, Teresa Eleurério. de. A escrita da repressão e da subversão. Rio de Janeiro: Arquivo Nacional, 2012.

JOFFILY, Mariana. Direito à informação e direito à vida privada: os impasses em torno do acesso aos arquivos da ditadura militar brasileira. Estudos Históricos. Rio de Janeiro, v. 25, p. 129-148, 2012.

SANTANA, Marco Aurélio. Homens partidos: comunistas e sindicatos no Brasil. São Paulo, Boitempo Editorial/UFRJ, 2001.

RIOUX, Jean-Pierre Pode-se fazer uma história do presente? In. CHAUVEAU. Agnès; TÉTARD, Philippe. (Orgs.). Questões para a história do presente. Bauru: Edusc, 1999, p. 39-50.

SILVA, Francisco Carlos Teixeira. "Crise da Ditadura Militar e o processo de abertura política no Brasil, 1974-1985". In: FERREIRA, Jorge; DELAGADO, Lucilia de Almeida Neves (Orgs). O Brasil republicano vol. 4: o tempo da ditadura - regime militar e movimentos sociais em fins do século XX. Rio de Janeiro: Civilização Brasileira, 2003. p. 260. 
Recebido em 29/02/2016 Aprovado em 19/04/2016

Universidade do Estado de Santa Catarina - UDESC Programa de Pós-Graduação em História - PPGH Revista Tempo e Argumento Volume 08 - Número 17 - Ano 2016 tempoeargumento@gmail.com 